\title{
Characterization of mitochondrial replication and transcription control during rat early development in vivo and in vitro
}

\author{
Yuichi Kameyama ${ }^{1,2}$, France Filion ${ }^{1}$, Jae Gyu Yoo ${ }^{1}$ and Lawrence C Smith ${ }^{1}$ \\ ${ }^{1}$ Faculté de Médecine Vétérinaire, Centre de Recherche en Reproduction Animale, Université de Montréal, \\ Saint-Hyacinthe, Québec, Canada J2S7C6 and ${ }^{2}$ Faculty of Bioindustry, Tokyo University of Agriculture, Abashiri, \\ Hokkaido 099-2493, Japan \\ Correspondence should be addressed to L C Smith; Email: smithl@medvet.umontreal.ca
}

\begin{abstract}
In vitro culture (IVC), used in assisted reproductive technologies, is a major environmental stress on the embryo. To evaluate the effect of IVC on mitochondrial transcription and the control of mtDNA replication, we measured the mtDNA copy number and relative amount of mRNA for mitochondrial-related genes in individual rat oocytes, zygotes and embryos using real-time PCR. The average $m t D N A$ copy number was $147600( \pm 3000)$ in metaphase II oocytes. The $m t D N A$ copy number was stable throughout in vivo early development and IVC induced an increase in mtDNA copy number from the 8-cell stage onwards. Gapd mRNA levels vary during early development and IVC did not change the patterns of these housekeeping gene transcripts. Polrmt mRNA levels did not vary during early development up to the morula stage but increased at the blastocyst stage. IVC induced the up-regulation of Polrmt mRNA, one of the key genes regulating mtDNA transcription and replication, at the blastocyst stage. An increase in mt-Nd4 mRNA preceded the blastocyst-related event observed in nuclear-encoded Gapd and Polrmt, suggesting that the expression of mitochondrial encoded genes is controlled differently from nuclear encoded genes. We conclude that the IVC system can perturb mitochondrial transcription and the control of mtDNA replication in rat embryos. This perturbation of mtDNA regulation may be responsible for the abnormal physiology, metabolism and viability of in vitro-derived embryos. Reproduction (2007) 133 423-432
\end{abstract}

\section{Introduction}

Rats are the most widely studied experimental animal models in toxicology. In this field, embryo culture methods have become important tools for elucidating the prenatal toxicity of chemicals (Stahlmann et al. 1993) and whole embryo culture systems have been developed to assess malformation and embryo toxicity after implantation (Webster et al. 1997). However, no in vitro screening test has been established during rat early development, partially due to inadequate culture systems for preimplantation stage embryos. Nonetheless, some in vitro culture systems have recently been developed for the culture of zygotes through the blastocyst stage in several strains of rats (Miyoshi et al. 1997, Zhou et al. 2003). These systems could provide not only a beneficial tool for the assessment of environmental stress but also a powerful tool for the development of reproductive technologies in rats.

Optimized in vitro culture (IVC) systems for the preimplantation stages of development are critical components for most human and animal assisted reproductive technologies. For instance, it is known that IVC conditions can have a profound effect on postimplantation development, including physiology, metabolism and viability (Khosla et al. 2001, Gardner \& Lane 2005). Moreover, reports have shown that the exposure of mouse embryos to suboptimum culture conditions can lead to long-term behavioral effects in the resultant offspring (Ecker et al. 2004, Fernandez-Gonzalez et al. 2004). On the other hand, a report has shown that embryo culture does not affect the longevity of offspring in mice (Sommovilla et al. 2005). Recently, IVC has been shown to be correlated with significant up- or down-regulation, de novo induction or silencing of genes critical for fetal and neonatal development (de A Camargo et al. 2005, Gardner \& Lane 2005, Wrenzycki et al. 2005), indicating that the comparison of gene expression patterns between in vivo and in vitro embryos is a reasonable index to develop IVC systems in different mammals.

Mitochondria play a key role in the physiology of eukaryotic cells during all stage of life including the preimplantation period and their main function is to provide cells with ATP through oxidative phosphorylation 
(Bavister \& Squirrell 2000, Brenner et al. 2004, Cummins 2004, Smith et al. 2005). Mitochondria contain their own genome and mitochondrial DNA (mtDNA) encodes 13 essential components of the oxidative phosphorylation pathway, including six NADH dehydrogenase subunits (mt-Nd1 to 6) of Complex I. The remaining genes required for mitochondrial function, more than 200 (Cummins 2004), are transferred to the nuclear genome during the evolutionary process. Consequently, mitochondria rely on nuclear-encoded products not only to produce the remaining oxidative phosphorylation component, but also to provide direct support for general housekeeping tasks and for other important physiological roles (i.e. in apoptosis and steroidogenesis; Smith et al. 2005). Although the mechanisms, which regulate the amounts of mitochondrial mRNA and DNA molecules remain elusive, studies in somatic cells have indicated that mtDNA transcription, and the subsequent use of nascent RNA to prime its replication, involves a nuclear-encoded RNA polymerase (Polrmt) and the mitochondrial-specific transcription factors Tfam and Tfb2 (Clayton 2000, 2003, Moraes 2001, Gaspari et al. 2004).

Little is known about mtDNA replication and transcriptional events in mammalian oocytes, zygotes and early embryos. The mitochondrial copy number has been reported in oocytes from mice (Piko \& Taylor 1987, Thundathil et al. 2005), bovines (Smith et al. 2005), pigs (El Shourbagy et al. 2006) and humans (Steuerwald et al. 2000, Reynier et al. 2001, May-Panloup et al. 2005a) but, to date, there is no report of the mDNA copy number in rat oocytes. Pioneering studies by Piko \& Taylor (1987) showed that the quantity of mtDNA remains stable throughout early development in mice, suggesting an absence of mtDNA replication during preimplantation; however, it has been suggested that there is a very short period of mtDNA synthesis immediately after fertilization in mice, which can be affected by environmental stress (McConnell \& Petrie 2004). In an attempt to clarify the control of mitochondrial function, we have recently shown dynamic changes in the transcription patterns of mitochondrial and nuclear genes that encode mitochondrial transcription and replication factors, suggesting that most molecular components are available for mtDNA replication pre-implantation (Thundathil et al. 2005). Previous studies clearly indicated the tight coordination of nuclear and mitochondrial OXPHOS transcripts during early development (Taylor \& Piko 1995). Moreover, a recent study implied that mitochondria directly influence fertilization outcome and subsequent embryonic development in pigs (El Shourbagy et al. 2006).

We hypothesize that IVC, a major environmental stress on embryos used in assisting reproductive technologies, may perturb mitochondrial transcription and the control of $m t D N A$ replication. Since, few reports have focused on improving culture systems for rats, the object of this study is to evaluate the effect of in vitroculture on the molecular control of nuclear-mitochondrial interactions during rat early development. In pursuit of this objective, we measured the mtDNA copy number and relative amount of mRNA for mitochondrial-related genes in individual rat oocytes, zygotes and embryos using real-time PCR.

\section{Materials and Methods}

\section{Chemical source}

Unless otherwise noted, all chemicals and reagents were purchased from Sigma Chemicals Co.

\section{Animal source}

The rats were obtained from Charles River Canada (St-Constant, Québec, Canada) and kept on a $14 \mathrm{~h}$ light:10 h dark schedule (dark period peaked at midnight). Female Sprague-Dawley (SD) rats (6-10 week old) were used to collect oocytes and to mate with male Brown Norway rats to obtain fertilized embryos. All animal treatment protocols were approved by the Comité de Déontologie, Faculté de Médecine Vétérinaire, Université de Montréal in accordance with the regulations of the Canadian Council of Animal Care.

\section{Oocyte, zygote and embryo sampling}

Oocytes were collected from superovulated females injected with eCG (15 IU, Folligon, Intervet, Ontario, Canada) followed $48 \mathrm{~h}$ later by hCG (25 IU, Chorulon, Intervet). Oocytes were collected from oviducts at 14-15 h after hCG injection using Hepes-buffered $\mathrm{K}$ modified simplex optimized medium (KSOM) (H-KSOM; Lawitts \& Biggers 1993). Cumulus cells were removed by pipetting $\mathrm{H}-\mathrm{KSOM}$ containing hyaluronidase $(20 \mathrm{lU} / \mathrm{ml})$.

Zygotes (1-cell stage) were collected from natural ovulated and superovulated females. Proestrus females selected by vaginal smear (natural ovulation) and an eCG-hCG primed female (superovulation) were caged overnight with fertile males and killed at $1500 \mathrm{~h}$ the following day (24 h after hCG injection). Zygotes recovered from superovulated females were cultured using a two-phase chemically defined system (Zhou et al. 2003) comprised of culture for the first $18 \mathrm{~h}$ in KSOM (Lawitts \& Biggers 1993), then in mR1ECM (Miyoshi et al. 1997) up to $120 \mathrm{~h}$. In vitro-derived early 2-cell embryos, late 2-cell embryos, 8-cell embryos, morulae and blastocysts were selected and sampled at 24, 48, 72, 96 and $120 \mathrm{~h}$ of culture respectively. On the other hand, in vivo-derived early 2-cell embryos, late 2-cell embryos, 8-cell embryos, morulae and blastocysts were sampled from naturally mated females at $1500 \mathrm{~h}$ on day $2,0900 \mathrm{~h}$ on day $3,0700 \mathrm{~h}$ on day 4, $0300 \mathrm{~h}$ on day 5 and $1500 \mathrm{~h}$ on day 5 respectively (day $1=$ the day of sperm detection in vaginal smear). Only morphologically excellent oocytes, zygotes and embryos were washed with PBS containing $0.1 \%$ (W/V) polyvinyl 
alcohol (PVA), loaded individually into a siliconized $1.5 \mathrm{ml}$ tube with less than $5 \mu \mathrm{l}$ of the PBS and stored at $-70{ }^{\circ} \mathrm{C}$ until use.

\section{Isolation of genomic DNA and mRNA}

Genomic DNA and mRNA were isolated from each individual oocyte, zygote or embryo with oligo-dt conjugated beads using Dynabeads mRNA Direct Kit (Dynal, Oslo, Norway) according to the manufacturer's protocol with modifications. Briefly, 5 pg rabbit globin mRNA (Sigma) was added to each sample as an external standard. Each oocyte, zygote or embryo was lysed in $100 \mu \mathrm{l}$ of lysis/binding buffer by gentle vortexing for $10 \mathrm{~min}$ and $10 \mu \mathrm{l}$ of prewashed beads were added to the fluid. After a second gentle vortexing for $10 \mathrm{~min}$, the beads were separated with a magnetic separator (Dynal) and the supernatant was used for the extraction of genomic DNA. mRNA was eluted from the beads by incubation in $10 \mu \mathrm{l}$ sterile water at $70{ }^{\circ} \mathrm{C}$ for $3 \mathrm{~min}$ and reverse transcribed (RT) into cDNA using a Sensiscript RT Kit (Qiagen) according to the manufacturer's protocol. Reverse transcriptase was omitted during the RT reaction in the negative controls. The CDNA was purified with $0.8 \mu \mathrm{g}$ of MS2 carrier RNA (Roche Diagnostics) using MinElute Reaction Cleanup Kit (Qiagen) according to the manufacturer's protocol and eluted twice with $11 \mu \mathrm{l}$ sterile water. Carrier RNA (333 ng, Qiagen) was added to each sample before genomic DNA extraction (QIAmp DNA mini kit, Qiagen), eluted twice with $50 \mu \mathrm{l}$ of sterile water and diluted ten times for quantitative PCR. Both cDNA and genomic DNA were used for quantitative PCR on the day of extraction to avoid degradation.

\section{Primer design}

Primer pairs for the relative quantification of gene expression and absolute quantification of mtDNA copy number are listed in Table 1. Primers of Gapd, Polrmt and $m t-N d 4$ were designed using published rat cDNA sequences (GenBank, NM_017008, XM_216836 and
NC_001665 respectively). Primers for the quantification of mtDNA were designed from homologous regions of $16 \mathrm{~S}$ rRNA genes in published mitochondrial sequences of rats (NC_001665).

\section{Absolute quantification of mitochondrial DNA copy number}

Quantification standards were prepared according to our previous report (Thundathil et al. 2005). A long 1333 bp fragment between $16 \operatorname{SrRNA}$ and ND1 region of mtDNA was amplified from rat liver by PCR using primer pair 5'-ATA ATC ACT TGT TCC TTA ATT AG-3' and 5'-CTA ATT CTG ATT CTC CTT CTG-3'. The PCR product was extracted from the gel using QIAquick Gel Extraction Kit (Qiagen) and cloned using QIAGEN PCR Cloning Kit. The plasmid DNA was purified using QIAprep Spin Miniprep Kit (Qiagen), quantified by spectrophotometer and diluted at $1 \times 10^{7}$ copies/ $\mu \mathrm{l}$. To simulate embryo samples, $10 \mu \mathrm{l}$ of standard stock was extracted and serially diluted for use in the standard curve. Real-time fluorescent monitored quantitative PCR was performed in a LightCycler (Roche) as described in our previous report (Thundathil et al. 2005) with modifications. The PCR program employed an initial step of $95{ }^{\circ} \mathrm{C}$ for 5 min followed by 45 cycles of $3 \mathrm{~s}$ at $94{ }^{\circ} \mathrm{C}$ for denaturation, $2 \mathrm{~s}$ at $62{ }^{\circ} \mathrm{C}$ for annealing, and $10 \mathrm{~s}$ at $72{ }^{\circ} \mathrm{C}$ for elongation. The melting curve of the amplified product was achieved at $95^{\circ} \mathrm{C}$ for $5 \mathrm{~s}, 55^{\circ} \mathrm{C}$ for $5 \mathrm{~s}$, and $99{ }^{\circ} \mathrm{C}$ for $0 \mathrm{~s}$. Cooling was done at $40^{\circ} \mathrm{C}$ for $10 \mathrm{~s}$. Temperature transition rates were set at $20^{\circ} \mathrm{C} / \mathrm{s}$ except for the final melting step $\left(0.1^{\circ} \mathrm{C} / \mathrm{s}\right)$. A fluorescent signal was acquired continuously at the end of elongation for quantification and the final melting step to identify the PCR product. Premix for quantitative PCR was prepared from LightCycler FastStart DNA Master SYBR Green I (Roche). The premix consisted of $5.4 \mu \mathrm{l}$ of PCR grade water, $1.6 \mu \mathrm{l}$ of $25 \mathrm{mM} \mathrm{MgCl}_{2}, 2 \mu \mathrm{l}$ of hot start reaction mix, and $1 \mu \mathrm{l}$ of $10 \mathrm{mM}$ primer pair and $10 \mu \mathrm{l}$ of DNA template was added to $10 \mu \mathrm{l}$ of premix for PCR reaction.

Table 1 Primers for real-time PCR.

\begin{tabular}{|c|c|c|c|}
\hline Purpose & Gene & Sequence & Product size (bp) \\
\hline \multirow[t]{4}{*}{ Relative quantification of gene expression } & Gapd & $\begin{array}{l}\text { CAT TGT TGC CAT CAA CGA CC } \\
\text { GTA GAC TCC ACG ACA TAC TC }\end{array}$ & 210 \\
\hline & Polrmt & CCT ACA CTG CTA CAG GAA G & 242 \\
\hline & & GCA AGG ATC GTA GTG TCT C & \\
\hline & $m t-N d 4$ & ATA ATT ATA ACT AGC TCA ATC TGC & 200 \\
\hline \multirow[t]{2}{*}{ External control of gene expression } & Rabbit $\alpha-1$-globin ${ }^{\mathrm{a}}$ & GCA GCC ACG GTG GCG AGT AT & 257 \\
\hline & & GTG GGA CAG GAG CTT GAA AT & \\
\hline Absolute quantification of mtDNA copy number & $m t D N A$ & $\begin{array}{l}\text { TTG ATC AAC GGA CCA AGT TAC } \\
\text { CTG GAT TGC TCC GGT CTG A }\end{array}$ & 185 \\
\hline
\end{tabular}

${ }^{a}$ Wrenzycki et al. (1999). 


\section{Relative quantification of mRNA amounts}

The standard was prepared with mRNA from rabbit globin (Sigma), reverse transcribed, purified, amplified by PCR, extracted from the gel and cloned. Plasmid DNA was purified, quantified and serially diluted to 1000, $100,10,1,0.1,0.01$ and $0.005 \mathrm{fg} / \mu \mathrm{l}$. With the exception of denaturation at $95{ }^{\circ} \mathrm{C}$ for $5 \mathrm{~s}$ and annealing at $58{ }^{\circ} \mathrm{C}$ for $5 \mathrm{~s}$, quantitative PCR was performed as described above. cDNA templates for individual embryos were recovered and used for amplification of the globin standard, Gapd, Polrmt and $\mathrm{mt}-\mathrm{Nd} 4$. A premix was prepared consisting of $8.9 \mu \mathrm{l}$ of PCR grade water, $1.6 \mu \mathrm{l}$ of $25 \mathrm{mM} \mathrm{MgCl}_{2}, 0.5 \mu \mathrm{l}$ of DMSO, $2 \mu \mathrm{l}$ of hot start reaction mix and $1 \mu \mathrm{l}$ of $10 \mathrm{mM}$ primer pair.

\section{Cell number count of blastocyst}

Some blastocysts were fixed with $10 \%(\mathrm{v} / \mathrm{v})$ neutralbuffered formalin for $15 \mathrm{~min}$ and permeabilized overnight with PBS containing $0.5 \%(\mathrm{w} / \mathrm{v})$ Triton $\mathrm{X}-100$ and $0.1 \%(\mathrm{w} / \mathrm{v})$ polyvinyl alcohol. Blastocysts were stained with $0.1 \mu \mathrm{g} / \mathrm{ml}$ of Hoechst dye 33342 (Sigma) and nuclei were counted under a fluorescent microscope.

\section{Statistical analysis}

All data were analyzed by one-way ANOVA followed by Tukey honest significance differences and a probability of $P<0.05$ was considered statistically significant.

\section{Results}

\section{Development of in vitro cultured zygotes}

To assess the efficiency of our culture system, we recorded the developmental rate of 1-cell stage zygotes at different periods of in vitro culture (Table 2). Almost all zygotes had already cleaved by $24 \mathrm{~h}$ and remained at the 2 -cell stage until $48 \mathrm{~h}$ of culture. At $72 \mathrm{~h}$ of culture, more than $90 \%$ of cultured zygotes had developed to either the 4-cell or non-compacted 8-cell stage. Most of the 4-cell and 8-cell stage embryos developed to the early or non-expanded blastocyst stage at $96 \mathrm{~h}$ of culture. Maximum blastocyst development (81\%) was obtained at $120 \mathrm{~h}$ of culture, indicating that the culture system was able to support in vitro development from zygote to blastocyst efficiently.

Comparisons between in vitro- and in vivo-derived embryos should preferably be made among counterparts at similar stages of development. Since, preliminary experiments had indicated that in vivo embryos were further advanced in development at fixed time points, adjustments to the timing of collection were required to obtain similar embryo stages for comparison. Therefore, we examined the developmental rate of in vivo embryos by continuous sampling throughout preimplantation (data not shown) and brought forward the sampling time to obtain the morphological stages (late 2-cell, 8-cell, morula and blastocyst stage embryos) obtained in vitro. These results clearly show that embryos derived from our in vitro culture system cleave at a slower rate than in vivo embryos. The cell number of cleavage stage embryos can be readily assessed by live microscopy, whereas morula (data not shown) and blastocysts derived in vivo and from in vitro cultures were assessed by live microscopy (Fig. 1A and B) and after fixation and DNA staining to count the nuclei number (Fig. 1C and D). Blastocysts derived in vitro were morphologically different from those derived in vivo. Blastocysts derived in vitro were expanding and in some cases already hatching at the time of harvesting (Fig. 1B), whereas blastocysts derived in vivo had an oval shape and a large perivitelline space (Fig. 1A). Nonetheless, the total cell number of blastocysts derived in vitro $(37.8 \pm 1.2, n=52$, Fig. 1D) was remarkably similar to that derived in vivo $(38.0 \pm 1.5, n=26$, Fig. 1C), indicating that the molecular parameters (mtDNA copy number and mRNA abundance) could be compared among the in vivo and in vitro groups.

\section{Mitochondrial DNA copy number of in vivo and in vitro embryos}

To verify whether the culture system used to obtain embryos in vitro had an effect in the mechanisms controlling mtDNA levels during early embryogenesis, we quantified the mtDNA copy numbers of in vivo- and in vitro-derived embryos from zygote to blastocyst stages (Fig. 2). The mean mtDNA copy number in rat metaphase II oocytes was $147600( \pm 3000, n=11)$ with small oocyte variation (123 400-156 900). Since,

Table 2 Developmental stage of cultured rat zygotes at sampling.

Developmental stage

\begin{tabular}{|c|c|c|c|c|c|c|c|c|c|}
\hline \multirow[b]{2}{*}{$\begin{array}{l}\text { Duration of } \\
\text { culture }(\mathrm{h})\end{array}$} & \multirow[b]{2}{*}{$\begin{array}{l}\text { No. of } \\
\text { replicates }\end{array}$} & \multirow[b]{2}{*}{$\begin{array}{l}\text { No. of ova } \\
\text { observed }\end{array}$} & \\
\hline & & & 1-cell (\%) & 2 -cell (\%) & 4-cell $(\%)$ & 8 -cell (\%) & Morula (\%) & Blastocyst (\%) & Fragmented (\%) \\
\hline 24 & 4 & 41 & 2 & 98 & & & & & \\
\hline 48 & 4 & 44 & 2 & 95 & 2 & & & & \\
\hline 72 & 5 & 108 & 1 & 4 & 52 & 42 & & & 2 \\
\hline 96 & 5 & 94 & 1 & 1 & 6 & 9 & 51 & 28 & 4 \\
\hline 120 & 6 & 161 & 2 & 4 & 2 & 1 & 8 & 81 & 3 \\
\hline
\end{tabular}



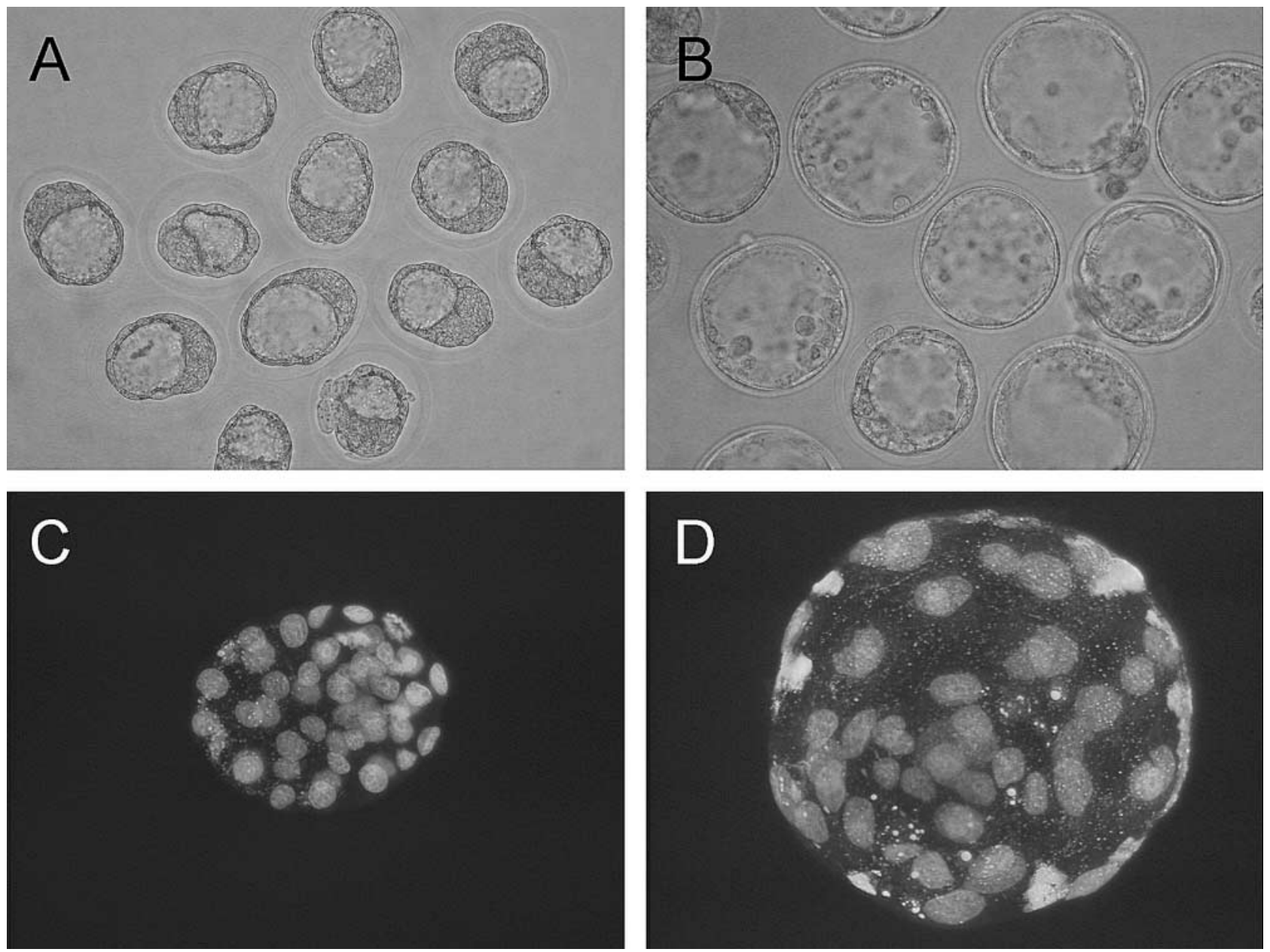

Figure 1 Optical $(A$ and $B, \times 20)$ and fluorescence $(C$ and $D, \times 40)$ microscopic images of in vivo-derived $(A$ and $C)$ and in vitro-derived $(B$ and $D)$ rat blastocysts.

in vitro cultured embryos were recovered from eCGstimulated females, we compared the mtDNA copy number per zygote between naturally ovulated $(\mathrm{NO})$ and superovulated (SO) females. There was no significant difference in the mean mtDNA copy number ( \pm s.E.M.) between the two groups (NO: $127134 \pm 4780, n=14$, SO: $124869 \pm 4962, n=14)$. From these results, we conclude that SO does not affect the mtDNA copy number in zygotes used for in vitro culture. Our next step was to compare the mtDNA copy number between in vivo- and in vitro-derived embryos from the early 2 -cell to blastocyst stages. There were no significant differences at early 2-cell (in vivo: $137018 \pm 5692$, $n=11$; in vitro: $139478 \pm 4500, n=9$ ), late 2 -cell (in vivo: $149833 \pm 7870, n=12$; in vitro: $150860 \pm$ $7255, n=10$ ) and 8-cell stages (in vivo: $141882 \pm 767 \overline{6}$, $n=11$; in vitro: $164930 \pm 7861, n=10$ ); however, significant differences were observed at the morula (in vivo: $128995 \pm 5224, n=13$; in vitro: $166222 \pm$ $3733, n=9$ ) and blastocyst stages (in vivo: $129400 \pm$ $10499, n=14$; in vitro: $166416 \pm 11829, n=14)$, indicating that the in vitro culture environment can affect the control of mtDNA copy number during the later stages of preimplantation development. Finally, we also compared the mtDNA copy number among the different developmental stages within the in vivo

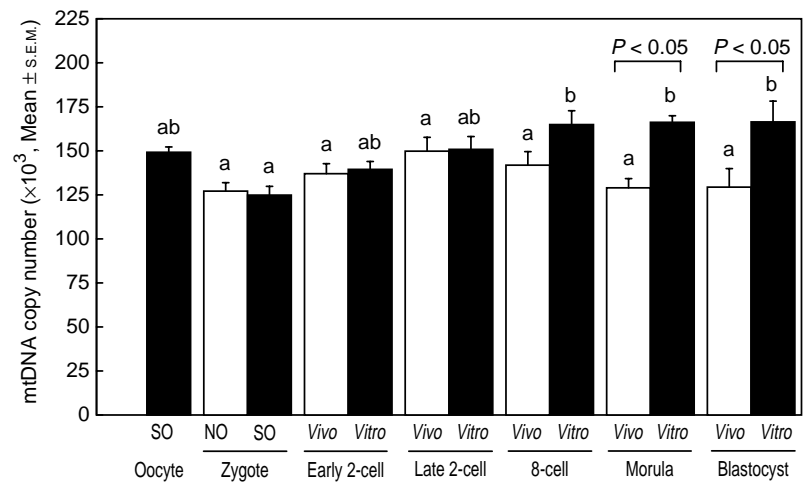

Figure 2 Mitochondrial DNA copy number in rat oocytes, zygotes (derived from $\mathrm{NO}$ and $\mathrm{SO}$ ) and embryos (derived in vivo and in vitro). Data were collected from at least four reactions. Developmental stages not connected by the same letter are significantly different $(P<0.05)$. 
(including NO-derived zygotes) and in vitro (including SO-derived oocytes and zygotes) groups. In the in vivo group, the mtDNA copy number was stable $(P>0.05)$ throughout early development, i.e. from the zygote to blastocyst stage. On the other hand, the mtDNA copy number of in vitro-derived 8-cell, morula and blastocyst embryos was significantly higher than in zygotes $(P<0.05)$. These results confirm that the in vitro culture conditions induce an increase in the mtDNA copy number from the 8-cell stage onwards.

\section{Transcript amounts of in vivo and in vitro embryos}

To determine whether the increase in the mtDNA copy number of in vitro-derived embryos was related to transcriptional alterations, we quantified the relative mRNA amounts of glyceraldehydes-3-phosphate dehydrogenase $(G a p d)$, nuclear-encoded mitochondrial RNA polymerase (Polrmt), and NADH dehydrogenase subunit $4(m t-N d 4)$ in oocytes (SO $n=8)$, zygotes (NO $n=5$, SO $n=6$ ), early 2 -cell (in vivo $n=6$, in vitro $n=5$ ), late 2 -cell (in vivo $n=6$, in vitro $n=6$ ), 8 -cell (in vivo $n=9$, in vitro $n=7$ ), morula (in vivo $n=5$, in vitro $n=6$ ) and blastocyst (in vivo $n=5$, in vitro $n=5$ ) -stage embryos. The amount of Gapd mRNA remained low and stable until the 8-cell stage but increased significantly in morula (in vitro embryo) and blastocyst stages (in vivo and in vitro embryos; Fig. 3). There was no significant difference in the amount of Gapd mRNA between in vivo and in vitro embryos during early development. These results indicate that the expression of Gapd varies during early development and the culture system used in these experiments does not change the patterns of expression of this housekeeping gene.

The relative amount of Polrmt mRNA was measured to determine whether nuclear-mitochondrial interactions were disturbed by the in vitro systems used to culture rat preimplantation-stage embryos (Fig. 4). As for Gapd,

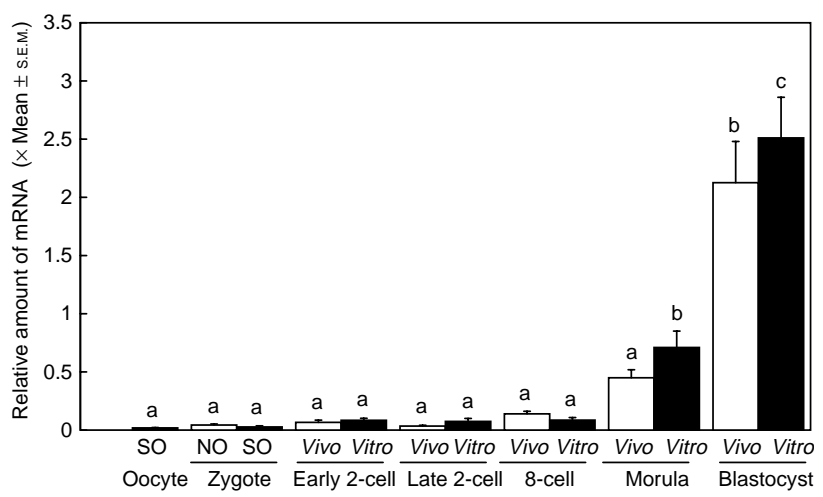

Figure 3 Relative amount of Gapd mRNA in rat oocytes (derived from $\mathrm{SO}$ ), zygotes (derived from $\mathrm{NO}$ and $\mathrm{SO}$ ) and embryos (derived in vivo and in vitro). Data were collected from at least three reactions. Developmental stages not connected by the same letter are significantly different $(P<0.05)$.

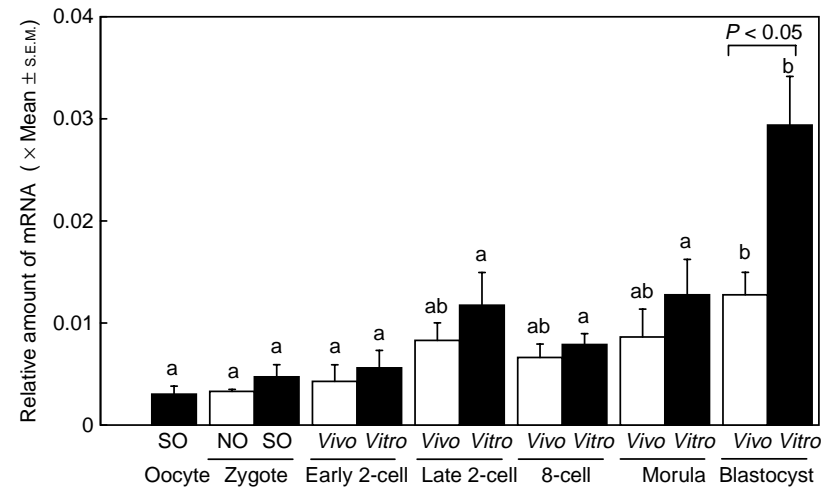

Figure 4 Relative amount of Polrmt mRNA in rat oocytes (derived from $\mathrm{SO}$ ), zygotes (derived from $\mathrm{NO}$ and $\mathrm{SO}$ ) and embryos (derived in vivo and in vitro). Data were collected from at least three reactions. Developmental stages not connected by the same letter are significantly different $(P<0.05)$.

Polrmt mRNA levels did not vary significantly during early development up to the morula stage but increased significantly in blastocysts. Interestingly, a slight nonsignificant increase in Polrmt was observed at the late 2-cell stage, which had disappeared by the 8-cell stage. Moreover, mRNA amounts in blastocysts derived in vitro were twice as high as in in vivo-derived blastocysts $(P<0.05)$, indicating that the in vitro culture system induces an unusual up-regulation of Polrmt.

The levels of $m t-N d 4$ mRNA were assessed to determine whether the in vitro environment affected the regulation of mitochondrial-encoded transcripts during early development (Fig. 5). The amount of $m t-N d 4$ mRNA was relatively abundant throughout early development and the expression pattern was different from Gapd and Polrmt. For in vivo embryos, the amount of $m t-N d 4$ mRNA was increased at the late 2 -cell stage, slightly decreased at the 8-cell stage, and remained stable up to the blastocyst stage. The only significant difference was observed between early and

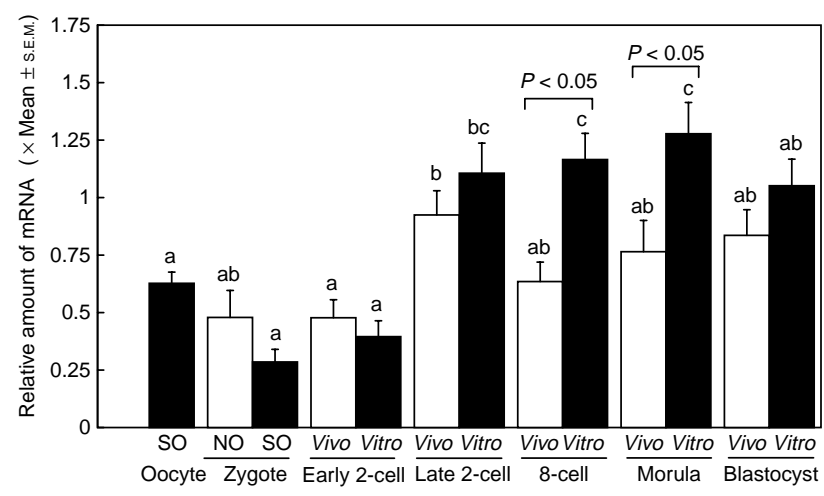

Figure 5 Relative amount of $m t-N d 4$ mRNA in rat oocytes (derived from $\mathrm{SO}$ ), zygotes (derived from $\mathrm{NO}$ and $\mathrm{SO}$ ) and embryos (derived from in vivo and in vitro). Data were collected from at least three reactions. Developmental stages not connected by the same letter are significantly different $(P<0.05)$. 
late 2-cell stages. On the other hand, $m t-N d 4$ mRNA of in vitro embryos was significantly increased at the late 2-cell stage and remained stable until the morula stage with a slight decrease at the blastocyst stage. Interestingly, the amount of $m t-\mathrm{Nd} 4 \mathrm{mRNA}$ in in vitro embryos was significantly higher than that in in vivo embryos at the 8-cell and morula stages of development. These results indicate that the increase in mitochondrial transcription precedes the later blastocyst-related event observed in the nuclear-encoded mitochondrial and housekeeping genes analyzed in this study. Moreover, increases in mitochondrial transcripts in the in vitro environment were larger and remained elevated during the more advanced stages of pre-implantation development.

\section{Discussion}

Artificial reproductive technologies are often utilized in the clinical setting to circumvent infertility problems, requiring the use of suitable experimental models to optimize in vitro culture systems that support early embryogenesis. Although mouse embryos have been widely used in the past, it is essential that another easily accessible laboratory species, i.e. the rat, be also examined to widen our understanding of conserved developmental requirements in other mammals. Due to the critical role mitochondria play on embryo survival, we have focused our attention on the effects of in vitro culture systems on this organelle and its interaction with the nucleus. Using an efficient culture system that supports the development of rat zygotes to the blastocyst stage, we demonstrate here that the in vitro environment significantly affects both mtDNA copy number and mitochondrial transcript abundance during preimplantation.

Previous reports have shown that rat zygotes, harvested at the syngamy-stage (14-16 h postovulation), cultured in vitro using a two-phase chemically defined system develop efficiently to the blastocyst stage (Zhou et al. 2003). The zygotes used in our study, which recovered at $24 \mathrm{~h}$ after hCG, were in the late pronuclear stage at recovery and, because ovulation occurs between 10 and $12 \mathrm{~h}$ after hCG (Holland et al. 2001), supposed to be comparable to zygotes at 12-14 h postovulation, Although our in vitro culture system provided enough embryos for research, the developmental speed was slower than in vivo and delayed development was observed from the 4-cell stage onwards. Since, genome activation of rat embryos occurs in the late 2-cell stage (Zernicka-Goetz 1994), in vitro embryos may have problems activating the transcription of the embryonic genome leading to the morphology of the resultant blastocysts being different from in vivo blastocysts. In vitro blastocysts raised in $\mathrm{mR} 1 \mathrm{ECM}$, which includes polyvinylalcohol instead of BSA (Miyoshi et al. 1997), may lead to the hardening of the zona pellucidae similarly to rat oocytes matured in vitro in serum-free medium (Zhang et al. 1991), which could prevent the hatching embryos cultured in vitro and cause morphological differences at the blastocyst stage. Therefore, although this culture system is capable of producing fertile offspring after embryo transfer (Zhou et al. 2003), we think that the system needs to be refined further.

To our knowledge, this is the first report of mtDNA copy number in rat oocyte and embryo. The mtDNA copy number in rat matured/ovulated oocyte in our result is close to that in mouse oocyte using dot hybridization (Piko \& Taylor 1987) or real-time quantitative PCR (Steuerwald et al. 2000, Thundathil et al. 2005). Ovarian hyperstimulation does not change the mtDNA copy number in metaphase II oocytes and the resultant embryos. This is a natural outcome, because fully grown germinal vesicle oocytes, responsible for eCG, have already accomplished mtDNA replication (Barritt et al. 2002). In bovine oocytes, we observed a slight decrease in the mtDNA copy number during the in vitro maturation process (Smith et al. 2005).

In the in vivo rat embryos, the mtDNA copy number was stable throughout early development, suggesting no replication of $\mathrm{mtDNA}$ during this period. However, IVC from the zygote stage induced an increase in mtDNA copy number from the 8-cell stage onward, suggesting that IVC can affect mtDNA replication during early development. A constant mtDNA copy number during in vivo early development is observed in mice (Piko \& Taylor 1987, Thundathil et al. 2005) and Piko \& Taylor (1987) suggested an absence of mtDNA replication during this period. On the other hand, we observed a significant increase in mtDNA copy number in in vitroproduced expanding and hatching blastocysts in bovines (Smith et al. 2005). Increasing mtDNA copy number in in vitro embryos can be interpreted as the following two possibilities: (1) accelerated mtDNA replication, which should occur after implantation; in mice, mtDNA replication is known to resume after the egg cylinder stage (Piko \& Matsumoto 1976, Ebert et al. 1988); (2) failure of mtDNA turnover immediately after fertilization. Recently, it was reported that there is a very short period of mtDNA synthesis from the 1-cell to 2-cell stage, which can be affected by environmental stress in mice (McConnell \& Petrie 2004). Further, May-Panloup et al. (2005a, 2005b) observed a decrease of mtDNA copy number during 2-cell to morula stage and the following increase at blastocyst stage in in vitro produced bovine embryo. Overall, mtDNA copy number is expressed as a result of balance between the synthesis and the degradation of mtDNA and in vitro production procedure including IVC could impair the balance.

The expression of Gapd as a housekeeping gene increased in the latter part of early development and IVC did not change the patterns of Gapd transcripts. This expression pattern agrees with that in in vivo mouse 
embryos (Thundathil et al. 2005), in vitro mouse embryos (Jeong et al. 2005) and in vitro-produced bovine embryos (Robert et al. 2002). The expression of Gapd could be a useful internal control not to compare between stages but for fixed stages. With the exception of HistonH2a in bovine embryos (Robert et al. 2002), no gene is known, which fulfils all the criteria throughout early development. Thundathil et al. (2005) reported that the expression pattern of Gapdh, Actb and HistonH2A in mouse embryo varied significantly during the period of preimplantation development. Gapd is an enzyme, which catalyzes an important energy-yielding step in carbohydrate metabolism and the expression of the housekeeping gene, including Gapd, is necessary for cell maintenance and proliferation. A suboptimal environment, which perturbs the expression of the housekeeping gene can lead directly to embryonic death. Embryos at the same stage contain the same amount of Gapd mRNA despite their in vivo or in vitro origin.

Polrmt mRNA levels were relatively low and did not vary during early development up to the morula stage, but IVC increased the levels of Polrmt mRNA, one of the key genes regulating mtDNA transcription and replication, at the blastocyst stage, more than twofold. In vitro procedures used in the production of fertilized and somatic nuclear transfer bovine embryos have been shown to be correlated with significant upor down-regulation, de novo induction or silencing of genes critical for undisturbed fetal and neonatal development (Wrenzycki et al. 2005). It is known that IVC causes down-regulation more frequently rather than up-regulation on the global pattern of gene expression in mouse embryos and most of this up-regulation was less than twofold (Rinaudo \& Schultz 2004); however, the expression pattern of Polrmt did not correspond completely with the change of mtDNA copy number. Mitochondrial RNA polymerase carries out the central activity of mitochondrial gene expression and, by providing RNA primers for replication, is also implicated in the maintenance and propagation of the mitochondrial genome (Tiranti et al. 1997). With in vivo embryos, a slight increase of Polrmt mRNA at the late 2-cell stage might be related to increased transcription of $m t-N d 4$ and further slight increase at the blastocyst stage might trigger mitochondrial replication after the egg cylinder stage (Piko \& Matsumoto 1976, Ebert et al. 1988). A subtle difference in the amount of Polrmt mRNA between in vivo and in vitro at the late 2-cell stage might cause a difference in the mtDNA copy number at morula and blastocyst stages. We speculate that small amounts of Polrmt mRNA could be sufficient for mitochondrial transcription and replication, or a positive feedback system for gene expression (Cross \& Tinkelenberg 1991) could explain the expression pattern of Polrmt. The first transcription and replication of mtDNA occurred by accumulated Polrmt mRNA during oogenesis and consumption of this
mRNA might stimulate de novo synthesis at the 2-cell stage; however, the unusual up-regulation of Polrmt mRNA in in vitro-derived blastocysts might significantly affect mitochondrial replication and transcription after implantation. On the other hand, for the expression pattern of Polrmt, the result eliminated the late 2-cell stage as a comparison, in vivo rat embryos are similar to in vivo mouse embryos (Thundathil et al. 2005); however, the increase of Polrmt mRNA in mice is more evident than in rats. Transcription in rat mtDNA might be less active than in mouse mtDNA. The Polrmt mRNA should increase at the same or the following stage in, which increased expression of promoters for Polrmt, like NRF1 (May-Panloup et al. 2005b) and Tfam (May-Panloup et al. 2005b, Thundathil et al. 2005), are observed. First, we tried to analyze expression pattern of Tfam, a key regulator for mitochondrial replication and transcription, which is essential for embryonic development (Larsson et al. 1998). Although Tfam mRNA was detectable in rat oocyte, the relative amounts were too low to get stable result (data not shown). Therefore, we changed the target gene to evaluate mitochondrilal replication and transcription from Tfam to Polrmt.

The amount of $m t-N d 4$ mRNA was relatively abundant throughout early development and the mitochondrialencoded $m t-N d 4$ gene could be actively transcribed from the 2-cell stage. In mice, it is reported that mitochondrial transcripts for Cox subunits are 30-50-fold more abundant than those derived from nuclear genes during early development (Taylor \& Piko 1995). Further, it is reported that the gene expression of nuclear-encoded Cox subunits, Cox5a, 5b, and 6b1, is not required for embryo developmental events up to the blastocyst stage in mice (Cui et al. 2006). The abundance of $m t-N d 4$ mRNA can be interpreted as a result of this overexpression in mitochondrial-encoded genes. (Hsieh et al. 2004) thought that polycistronic mtDNA transcripts are consistent, with different mtRNA expression levels showing the same pattern in oocytes. This could explain why the expression pattern of $\mathrm{mt}-\mathrm{Nd} 4$ in in vivo rat embryos is similar to that of other mitochondrial-encoded genes (COX I and COX II (Taylor \& Piko 1995), mt-Nd2 and $m t-N d 6$ (Thundathil et al. 2005)), in in vivo mouse embryos; however, the increase of mitochondrial genes in mice (Taylor \& Piko 1995, Thundathil et al. 2005) is higher than in rats. An increase in $m t-N d 4$ mRNA preceded the blastocyst-related event observed in nuclear-encoded genes and alterations induced by the in vitro environment were observed earlier during preimplantation development. This preceding increase could be related to import into mitochondria for the next step. Import is carried out by a complex, ATP-dependent transport system, followed by cleavage of the leader peptide, which eventually produces mature, functional protein (Neupert et al. 1990). The expression of mitochondrial-encoded genes might be controlled differently from nuclear-encoded genes. In this experiment, we saw a decreased amount of 
$m t-N d 4$ RNA in in vitro-derived blastocysts despite the normal morphology with an expanded blatocele cavity and a clear inner-cell-mass and normal expression level of Gapd as a housekeeping gene. This could be a symptom of cytoplasmic problems connected to embryonic death after implantation in in vitro-derived embryos.

PVA, one of the components in mR1ECM, might have affected the gene expression pattern of cultured embryo in the present study. Although modified R1ECM containing PVA instead of BSA is a common medium for the culture of rat embryo, replacement of BSA with PVA in culture media is known to impair hatching of blastocyst in mice (Biggers et al. 1997) and to affect amount of developmentally important gene transcripts in bovine blastocyst (Wrenzycki et al. 2001). Therefore, PVA could affect gene expression of rat embryos directly or indirectly via morphological changes related with hatching.

Recently, (Alizadeh et al. 2005) demonstrate the selective degradation of specific mRNAs after fertilization in mice. The amounts of mRNAs described in this study in zygotes were comparable to those in oocytes. It is possible that none of these mRNAs suffer selective degradation just after fertilization. Studies about the degradation of mRNA, de novo nascent mRNA synthesis, and resulting protein synthesis will give further insight into mitochondrial replication and transcription control during early development. Further, studies on mitochondrial distribution and the related proteins are needed to clarify the mitochondrial replication and transcription in mammalian early development.

From these results, the IVC system can perturb mitochondrial transcription and the control of mtDNA replication in mammalian embryos. This perturbation of mtDNA regulation may be responsible for the abnormal physiology, metabolism and viability of in vitro-derived embryos. Analysis of the gene expression pattern will be a good tool to develop an IVC system for reproductive technology in animals and humans.

\section{Acknowledgements}

This study was supported by the National Science and Engineering Research Council (NSERC) of Canada (LCS) and a competitive grant from Tokyo University of Agriculture (YK). The authors declare that there is no conflict of interest that would prejudice the impartiality of this scientific work.

\section{References}

Alizadeh Z, Kageyama S \& Aoki F 2005 Degradation of maternal mRNA in mouse embryos: selective degradation of specific mRNAs after fertilization. Molecular Reproduction and Development $\mathbf{7 2}$ 281-290.

Barritt JA, Kokot M, Cohen J, Steuerwald N \& Brenner CA 2002 Quantification of human ooplasmic mitochondria. Reproductive Biomedicine Online 4 243-247.
Bavister BD \& Squirrell JM 2000 Mitochondrial distribution and function in oocytes and early embryos. Human Reproduction $\mathbf{1 5}$ 189-198.

Biggers JD, Summers MC \& McGinnis LK 1997 Polyvinyl alcohol and amino acids as substitutes for bovine serum albumin in culture media for mouse preimplantation embryos. Human Reproduction Update 3 125-135.

Brenner CA, Kubisch HM \& Pierce KE 2004 Role of the mitochondrial genome in assisted reproductive technologies and embryonic stem cell-based therapeutic cloning. Reproduction, Fertility, and Development 16 743-751.

Clayton DA 2000 Transcription and replication of mitochondrial DNA. Human Reproduction 15 11-17.

Clayton DA 2003 Mitochondrial DNA replication: what we know. IUBMB Life 55 213-217.

Cross FR \& Tinkelenberg AH 1991 A potential positive feedback loop controlling CLN1 and CLN2 gene expression at the start of the yeast cell cycle. Cell 65 875-883.

Cui XS, Li XY, Jeong YJ, Jun JH \& Kim NH 2006 Gene expression of cox $5 \mathrm{a}, 5 \mathrm{~b}$, or $6 \mathrm{~b} 1$ and their roles in preimplantation mouse embryos. Biology of Reproduction 74 601-610.

Cummins JM 2004 The role of mitochondria in the establishment of oocyte functional competence. European Journal of Obstetrics, Gynecology, and Reproductive Biology 115 S23-S29.

de A Camargo LS, Powell AM, do Vale Filho VR \& Wall RJ 2005 Comparison of gene expression in individual preimplantation bovine embryos produced by in vitro fertilisation or somatic cell nuclear transfer. Reproduction, Fertility, and Development 17 487-496.

Ebert KM, Liem H \& Hecht NB 1988 Mitochondrial DNA in the mouse preimplantation embryo. Journal of Reproduction and Fertility $\mathbf{8 2}$ 145-149.

Ecker DJ, Stein P, Xu Z, Williams CJ, Kopf GS, Bilker WB, Abel T \& Schultz RM 2004 Long-term effects of culture of preimplantation mouse embryos on behavior. PNAS 101 1595-1600.

El Shourbagy SH, Spikings EC, Freitas M \& St John JC 2006 Mitochondria directly influence fertilisation outcome in the pig. Reproduction 131 233-245.

Fernandez-Gonzalez R, Moreira P, Bilbao A, Jimenez A, Perez-Crespo M, Ramirez MA, Rodriguez De Fonseca F, Pintado B \& Gutierrez-Adan A 2004 Long-term effect of in vitro culture of mouse embryos with serum on mRNA expression of imprinting genes, development, and behavior. PNAS 101 5880-5885.

Gardner DK \& Lane M 2005 Ex vivo early embryo development and effects on gene expression and imprinting. Reproduction, Fertility, and Development 17 361-370.

Gaspari M, Larsson NG \& Gustafsson CM 2004 The transcription machinery in mammalian mitochondria. Biochimica et Biophysica Acta 1659 148-152.

Holland AM, Findlay JK \& Clements JA 2001 Kallikrein gene expression in the gonadotrophin-stimulated rat ovary. Journal of Endocrinology 170 243-250.

Hsieh RH, Au HK, Yeh TS, Chang SJ, Cheng YF \& Tzeng CR 2004 Decreased expression of mitochondrial genes in human unfertilized oocytes and arrested embryos. Fertility and Sterility 81 912-918.

Jeong YJ, Choi HW, Shin HS, Cui XS, Kim NH, Gerton GL \& Jun JH 2005 Optimization of real time RT-PCR methods for the analysis of gene expression in mouse eggs and preimplantation embryos. Molecular Reproduction and Development 71 284-289.

Khosla S, Dean W, Reik W \& Feil R 2001 Culture of preimplantation embryos and its long-term effects on gene expression and phenotype. Human Reproduction Update 7 419-427.

Larsson NG, Wang J, Wilhelmsson H, Oldfors A, Rustin P, Lewandoski M, Barsh GS \& Clayton DA 1998 Mitochondrial transcription factor A is necessary for mtDNA maintenance and embryogenesis in mice. Nature Genetics 18 231-236.

Lawitts JA \& Biggers JD 1993 Culture of preimplantation embryos. Methods in Enzymology 225 153-164. 
May-Panloup P, Chretien MF, Jacques C, Vasseur C, Malthiery Y \& Reynier P 2005a Low oocyte mitochondrial DNA content in ovarian insufficiency. Human Reproduction 20 593-597.

May-Panloup P, Vignon X, Chretien MF, Heyman Y, Tamassia M, Malthiery Y \& Reynier P 2005b Increase of mitochondrial DNA content and transcripts in early bovine embryogenesis associated with up-regulation of mtTFA and NRF1 transcription factors. Reproductive Biology and Endocrinology 365.

McConnell JM \& Petrie L 2004 Mitochondrial DNA turnover occurs during preimplantation development and can be modulated by environmental factors. Reproductive Biomedicine Online 9 418-424.

Miyoshi K, Kono T \& Niwa K 1997 Stage-dependent development of rat 1-cell embryos in a chemically defined medium after fertilization in vivo and in vitro. Biology of Reproduction 56 180-185.

Moraes CT 2001 What regulates mitochondrial DNA copy number in animal cells? Trends in Genetics 17 199-205.

Neupert W, Hartl FU, Craig EA \& Pfanner N 1990 How do polypeptides cross the mitochondrial membranes? Cell 63 447-450.

Piko L \& Matsumoto L 1976 Number of mitochondria and some properties of mitochondrial DNA in the mouse egg. Developmental Biology 49 1-10.

Piko L \& Taylor KD 1987 Amounts of mitochondrial DNA and abundance of some mitochondrial gene transcripts in early mouse embryos. Developmental Biology 123 364-374.

Reynier P, May-Panloup P, Chretien MF, Morgan CJ, Jean M, Savagner F, Barriere P \& Malthiery Y 2001 Mitochondrial DNA content affects the fertilizability of human oocytes. Molecular Human Reproduction 7 425-429.

Rinaudo P \& Schultz RM 2004 Effects of embryo culture on global pattern of gene expression in preimplantation mouse embryos. Reproduction 128 301-311.

Robert C, McGraw S, Massicotte L, Pravetoni M, Gandolfi F \& Sirard MA 2002 Quantification of housekeeping transcript levels during the development of bovine preimplantation embryos. Biology of Reproduction 67 1465-1472.

Smith LC, Thundathil J \& Filion F 2005 Role of the mitochondrial genome in preimplantation development and assisted reproductive technologies. Reproduction, Fertility, and Development 17 15-22.

Sommovilla J, Bilker WB, Abel T \& Schultz RM 2005 Embryo culture does not affect the longevity of offspring in mice. Reproduction 130 599-601.

Stahlmann R, Klug S, Foerster M \& Neubert D 1993 Significance of embryo culture methods for studying the prenatal toxicity of virustatic agents. Reproductive Toxicology 7 129-143.

Steuerwald N, Barritt JA, Adler R, Malter H, Schimmel T, Cohen J \& Brenner CA 2000 Quantification of mtDNA in single oocytes, polar bodies and subcellular components by real-time rapid cycle fluorescence monitored PCR. Zygote 8 209-215.

Taylor KD \& Piko L 1995 Mitochondrial biogenesis in early mouse embryos: expression of the mRNAs for subunits IV, Vb, and VIIc of cytochrome c oxidase and subunit 9 (P1) of $\mathrm{H}(+)$-ATP synthase. Molecular Reproduction and Development 40 29-35.

Thundathil J, Filion F \& Smith LC 2005 Molecular control of mitochondrial function in preimplantation mouse embryos. Molecular Reproduction and Development 71 405-413.

Tiranti V, Savoia A, Forti F, D'Apolito MF, Centra M, Rocchi M \& Zeviani M 1997 Identification of the gene encoding the human mitochondrial RNA polymerase ( $\mathrm{h}-\mathrm{mtRPOL}$ ) by cyberscreening of the Expressed Sequence Tags database. Human Molecular Genetics 6 615-625.

Webster WS, Brown-Woodman PD \& Ritchie HE 1997 A review of the contribution of whole embryo culture to the determination of hazard and risk in teratogenicity testing. International Journal of Developmental Biology 41 329-335.

Wrenzycki C, Herrmann D, Carnwath JW \& Niemann H 1999 Alterations in the relative abundance of gene transcripts in preimplantation bovine embryos cultured in medium supplemented with either serum or PVA. Molecular Reproduction and Development 53 8-18.

Wrenzycki C, Herrmann D, Keskintepe L, Martins A Jr, Sirisathien S, Brackett B \& Niemann H 2001 Effects of culture system and protein supplementation on mRNA expression in pre-implantation bovine embryos. Human Reproduction 16 893-901.

Wrenzycki C, Herrmann D, Lucas-Hahn A, Korsawe K, Lemme E \& Niemann H 2005 Messenger RNA expression patterns in bovine embryos derived from in vitro procedures and their implications for development. Reproduction, Fertility, and Development 17 23-35.

Zernicka-Goetz M 1994 Activation of embryonic genes during preimplantation rat development. Molecular Reproduction and Development 38 30-35.

Zhang X, Rutledge J \& Armstrong DT 1991 Studies on zona hardening in rat oocytes that are matured in vitro in a serum-free medium. Molecular Reproduction and Development 28 292-296.

Zhou Y, Galat V, Garton R, Taborn G, Niwa K \& lannaccone P 2003 Two-phase chemically defined culture system for preimplantation rat embryos. Genesis 36 129-133.

Received 11 October 2006

First decision 9 November 2006

Accepted 27 November 2006 